\title{
CALIDAD NUTRICIONAL DE LA PLANTA DE RAMIO (Bohemeria nivea (L) GAUD) PARA ALIMENTACIÓN ANIMAL 1
}

\author{
Jorge Elizondo ${ }^{2}$, Carlos Boschini ${ }^{2}$
}

\begin{abstract}
RESUMEN
Calidad nutricional de la planta de ramio (Bohemeria nivea (L) Gaud) para alimentación animal. El presente experimento se llevó a cabo en la Estación Experimental de Ganado Lechero Alfredo Volio Mata, ubicada a $1542 \mathrm{msnm}$ con una precipitación anual media de $2050 \mathrm{~mm}$, temperatura media de $19,5{ }^{\circ} \mathrm{C}$ y una humedad relativa de $84 \%$. El propósito del experimento fue conocer la calidad nutricional de la planta de ramio cosechada en diferentes frecuencias de corte. Se utilizaron cuatro frecuencias de corte a los 42, 56, 70 y 84 días. Durante los muestreos se separaron las hojas del tallo y para cada muestra se determinó el contenido de materia seca, proteína cruda, fibra neutro detergente y cenizas. Se encontraron diferencias significativas $(\mathrm{P}<0,05)$ en la composición química de los diferentes componentes de la planta al considerar las frecuencias de corte. Al comparar el contenido de materia seca en el follaje entre los intervalos de corte de 42 y 84 días, se observa un incremento de un $34 \%$. El porcentaje de proteína cruda en hojas fue superior a $16,5 \%$, y el porcentaje de fibra neutro detergente fue siempre superior en tallo que en hoja.
\end{abstract}

\begin{abstract}
Nutritional quality of ramie (Bohemeria nivea (L) Gaud) for animal feed. This experiment was conducted at the Alfredo Volio Mata Dairy Cattle Experiment Station in Costa Rica, located at 1542 meters above sea level with an average annual rainfall of $2050 \mathrm{~mm}$, temperature of $19,5^{\circ} \mathrm{C}$ and a relative humidity of $84 \%$. The purpose of the experiment was to determine the nutritional quality of the ramie plant harvested at different frequencies. Four harvesting frequencies were used: 42, 56, 70 and 84 days. Dry matter, crude protein, neutral detergent fiber and ashes were analyzed for different parts of the plant. There were significant differences $(\mathrm{P}<0.05)$ in the chemical composition of the plant components. When comparing dry matter content in leaves between cutting intervals of 42 and 84 days, an increment of $34 \%$ was observed. Crude protein content in leaves was above to $16,5 \%$. Neutral detergent fiber was always higher in stems than in leaves.
\end{abstract}

\section{INTRODUCCIÓN}

Uno de los principales factores que limitan la buena alimentación de los animales en las explotaciones pecuarias tropicales, es la poca diversidad de forrajes con altos contenidos de energía o proteína, siendo necesario complementar las dietas con materias primas provenientes de otros países. Por ello, constantemente se buscan alternativas alimenticias de buena calidad, que permitan bajar los costos de alimentación en la producción animal. Esto se puede lograr mediante la utiliza- ción de fuentes forrajeras nutritivas cuyas características botánicas y agronómicas hagan posible su explotación de una forma económica y bajo las condiciones edafoclimáticas de nuestro país.

Una posibilidad es el cultivo de ramio (Bohemeria nivea (L) Gaud), que es una planta originaria de la China. Es una especie monoíca, dicotiledónea, perenne que pertenece a la familia de las Urticáceas. Tiene la cara inferior de las hojas cubierta con un indumento blanco. Es una planta herbácea que puede alcanzar de

\footnotetext{
1 Recibido para publicación el 7 de agosto del 2002. Inscrito en Vicerrectoría de Investigación No. 737-97-006

2 Estación Experimental Alfredo Volio Mata. Facultad de Ciencias Agroalimentarias.Universidad de Costa Rica. Tel: (506) 279-5840/ $279-5850$. E-mail: jaelizon@cariari.ucr.ac.cr, boschini@cariari.ucr.ac.cr.
} 
1,5 a 3,0 metros de altura, provista de tallos subterráneos o rizomas de donde brotan los tallos aéreos fibrosos. Las hojas son grandes, opuestas en forma alterna (Lasser 1956).

Se produce en climas tropicales y subtropicales, con suelos permeables. Requiere de lluvias constantes y uniformes a lo largo del ciclo vegetativo para su crecimiento. La precipitación favorable es de 2500 a 3000 mm anuales (Salazar 1981).

El ramio se ha cultivado principalmente para fines textiles (Rincón 1971) empleándose para ello el tallo, pero el follaje puede utilizarse como fuente de forraje verde para la alimentación de rumiantes, considerando que normalmente se desecha durante la extracción de tallos en las plantas industriales.

Las hojas y puntas, a diferencia de los tallos, son pobres en fibra y ricas en proteína, minerales, lisina y caroteno (Havard 1969)

Boschini y Rodríguez (2002) obtuvieron rendimientos de materia seca en hojas de 1210, 1837, 1925 y $1834 \mathrm{~kg} / \mathrm{ha} /$ corte a los 42, 56, 70 y 84 días, respectivamente. El ramio, cuando está tierno, contiene de 18 a $21 \%$ de proteína cruda (Himebauch 1967), lo que permite considerarlo como un forraje de alto valor proteíco.

El presente experimento se llevó a cabo con el fin de conocer la composición nutricional de la planta de ramio cosechada en diferentes frecuencias de corte.

\section{MATERIALES Y MÉTODOS}

El experimento se realizó en el año 2001, en la Estación Experimental Alfredo Volio Mata de la Universidad de Costa Rica, ubicada en el alto de Ochomogo en la provincia de Cartago. Su altitud es de $1542 \mathrm{msnm}$, con una precipitación media anual de $2050 \mathrm{~mm}$, distribuida en los meses de mayo a noviembre y una humedad relativa media de $84 \%$. La temperatura media anual es de $19,3^{\circ} \mathrm{C}$, alcanzando como máximo $23^{\circ} \mathrm{C}$ y como mínimo $13^{\circ} \mathrm{C}$. El suelo se clasifica como Tipic Dystrandepts (Vásquez 1982), formado por cenizas volcánicas recientes, con una textura franco arcillo arenoso, un pH de 5,8 y un contenido de materia orgánica de $6,24 \%$, con excelentes condiciones físicas y buenas características químicas, con vocación agrícola limitada por la topografía y buen drenaje. El ecosistema de la región se clasifica como bosque húmedo montano bajo (Tosi 1970, citado por Vásquez 1982).
El experimento se llevó a cabo en una plantación de ramio con tres años de establecimiento en un área de $3000 \mathrm{~m}^{2}$. La plantación se dividió en cuatro lotes correspondientes a las repeticiones. Al inicio del periodo experimental, se efectuó una poda de uniformización, llevada a cabo con machete a cinco centímetros sobre el nivel del suelo. Se aplicaron $75 \mathrm{~kg}$ de nitrógeno en forma de nitrato de amonio. Dicha fertilización se repitió tres meses después. Se empleó un diseño de bloques completos al azar (Steel y Torrie 1988), con cuatro tratamientos, cuatro repeticiones y cuatro observaciones desigualmente repetidas anidadas dentro de tratamientos. Así, dentro de cada lote de repetición se segregaron las parcelas correspondientes a los tratamientos de frecuencia de corte: 42, 56, 70 y 84 días, distribuidos al azar dentro de cada repetición. A partir de la fecha en que se realizó la uniformización, se programaron cinco cortes consecutivos cada 42 días, tres cortes cada 56 días y 70 días y dos cortes cada 84 días, dentro de un periodo experimental de 210 días.

Durante los muestreos realizados a nivel de campo, se separaron las hojas del tallo, ambas porciones se pesaron y se secaron a $60{ }^{\circ} \mathrm{C}$ durante 48 horas hasta alcanzar un peso constante. Finalmente, las muestras se molieron a $1 \mathrm{~mm}$ y se determinó el contenido de materia seca en una estufa a $105^{\circ} \mathrm{C}$, la proteína cruda por el método de Kjeldall y las cenizas totales (AOAC 1980). La fibra neutro detergente (FND) fue analizada con el método descrito por Goering y Van Soest (1970).

Los datos obtenidos se analizaron con el PROC GLM del paquete estadístico SAS (SAS 1985). Se efectuó la separación de medias con la prueba de Duncan, en aquellas variables que resultaron significativas.

\section{RESULTADOS Y DISCUSIÓN}

La composición química de la hoja, tallo y planta entera de ramio a diferentes frecuencias de corte, se presenta en el Cuadro 1.

\section{Calidad nutricional de la hoja}

El porcentaje de materia seca en la hoja muestra diferencias significativas $(\mathrm{P}<0,05)$ entre las diferentes frecuencias de corte. Al comparar estos contenidos entre los 42 y los 84 días, se observa un incremento de un $34 \%$. Caso contrario sucede con el porcentaje de proteína cruda, donde al comparar esas mismas frecuencias de corte, se observa una disminución de un $32 \%$. Esto 
Cuadro 1. Composición química de los diferentes componentes de la planta de ramio según la frecuencia de corte. Cartago, Costa Rica. 2001.

\begin{tabular}{|c|c|c|c|c|c|}
\hline & $\begin{array}{c}\text { Frecuencia } \\
\text { de corte } \\
\text { (días) }\end{array}$ & $\begin{array}{c}\text { Materia } \\
\text { seca } \\
(\%)\end{array}$ & $\begin{array}{c}\text { Proteína } \\
\text { cruda } \\
(\%)\end{array}$ & $\begin{array}{c}\text { Fib. Neutro } \\
\text { detergente } \\
(\%)\end{array}$ & $\begin{array}{c}\text { Cenizas } \\
(\%)\end{array}$ \\
\hline \multirow[t]{4}{*}{ Hoja } & 42 & $15,37 \mathrm{c}$ & $22,24 \mathrm{a}$ & $36,21 \mathrm{a}$ & $20,63 \mathrm{c}$ \\
\hline & 56 & $17,44 \mathrm{~b}$ & $19,70 \mathrm{~b}$ & $36,11 \mathrm{a}$ & $20,71 \mathrm{c}$ \\
\hline & 70 & $17,08 \mathrm{~b}$ & $18,68 \mathrm{c}$ & $34,10 \mathrm{~b}$ & $22,03 \mathrm{~b}$ \\
\hline & 84 & 20,63 a & $16,81 \mathrm{~d}$ & $32,10 \mathrm{c}$ & $23,49 \mathrm{a}$ \\
\hline \multirow[t]{4}{*}{ Tallo } & 42 & $8,69 \mathrm{~d}$ & $8,07 \mathrm{a}$ & $61,70 \mathrm{~d}$ & $12,18 \mathrm{a}$ \\
\hline & 56 & $11,79 \mathrm{c}$ & $5,88 \mathrm{~b}$ & $66,50 \mathrm{c}$ & $9,31 \mathrm{~b}$ \\
\hline & 70 & $12,83 \mathrm{~b}$ & $5,18 \mathrm{c}$ & $68,56 \mathrm{~b}$ & $8,38 \mathrm{c}$ \\
\hline & 84 & $15,95 \mathrm{a}$ & $4,66 \mathrm{~d}$ & 70,42 a & $7,94 \mathrm{~d}$ \\
\hline \multirow[t]{4}{*}{ Planta entera } & 42 & $12,32 \mathrm{c}$ & $15,77 \mathrm{a}$ & $47,85 \mathrm{c}$ & $16,77 \mathrm{a}$ \\
\hline & 56 & $14,56 \mathrm{~b}$ & $12,65 \mathrm{~b}$ & $50,63 \mathrm{~b}$ & $14,92 \mathrm{~b}$ \\
\hline & 70 & $14,86 \mathrm{~b}$ & $11,64 \mathrm{c}$ & 53,98 a & $14,90 \mathrm{~b}$ \\
\hline & 84 & 17,79 a & $9,45 \mathrm{~d}$ & $54,20 \mathrm{a}$ & $14,06 \mathrm{c}$ \\
\hline
\end{tabular}

a,b,c diferente letra en una misma columna marca una diferencia significativa $(\mathrm{P}<0,05)$.

concuerda con Bernal (1991), pues el porcentaje de proteína cruda decrece al aumentar la edad del forraje. Además existe una correlación negativa entre la concentración de materia seca y el contenido de nitrógeno del forraje.

En forma similar, el porcentaje de fibra neutro detergente y el porcentaje de cenizas muestran pequeñas diferencias entre las frecuencias de corte a 42 ó 56 días con las de 70 y 84 , las cuales resultan de importancia estadística $(\mathrm{P}<0,05)$. El porcentaje de fibra neutro detergente entre los 42 y los 84 días, presenta una disminución de un $13 \%$, mientras que el porcentaje de cenizas aumenta en un $14 \%$ al comparar las mismas frecuencias de corte.

En la Figura 1 se presentan los cambios en el porcentaje de materia seca, proteína cruda, fibra neutro detergente y cenizas presentes en la hoja de ramio según la frecuencia de corte. Se observa como el porcentaje de materia seca y de cenizas de la hoja, cortada a diferentes frecuencias de poda mostró un menor valor a los 42 días respecto al obtenido en los intervalos con mayor edad de rebrote. Contrariamente, el porcentaje de proteína cruda y fibra neutro detergente de la hoja muestra un mayor valor cuanto menor es el intervalo entre podas.

Los porcentajes de materia seca y proteína cruda obtenidos en este ensayo, coinciden con los publicados por Himebauch (1967), Mc Dowell, citado por Arauz (1984) y Blasco et al. citado por Hidalgo (1982).

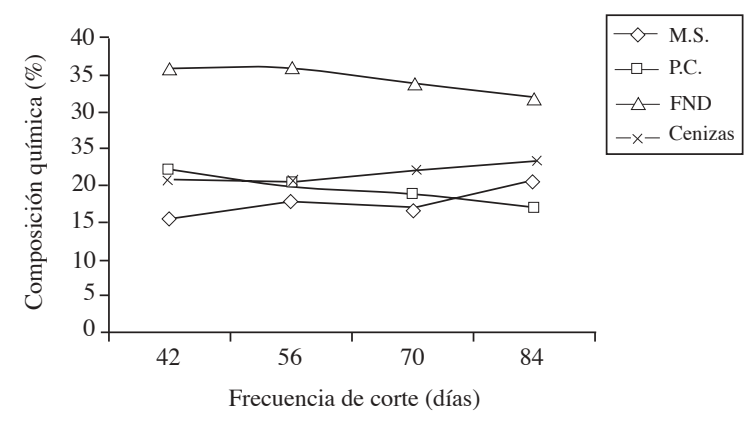

Figura 1. Composición química de la hoja de la planta de ramio cortada en diferentes frecuencias. Cartago, Costa Rica. 2001.

\section{Calidad nutricional del tallo}

Los diferentes componentes químicos presentes en el tallo varían significativamente $(\mathrm{p}<0,05)$ entre las diferentes frecuencias de corte. El porcentaje de materia seca reflejó un aumento progresivo al aumentar la edad de corte. Este aumento fue porcentualmente mucho mayor a aquel presentado en hoja, pasando de 8,69 a $15,95 \%$, lo que corresponde a un incremento de $84 \%$.

El contenido de fibra neutro detergente experimentó también un aumento al pasar de 61,70 a $70,42 \%$ de los 42 a 84 días de corte respectivamente. Es importante recalcar que el porcentaje de fibra neutro detergente fue siempre superior en tallos que en hojas.

En la Figura 2 se observa la variación existente en el porcentaje de materia seca, proteína cruda, fibra neutro detergente y cenizas presentes en tallo a diferentes frecuencias de corte.

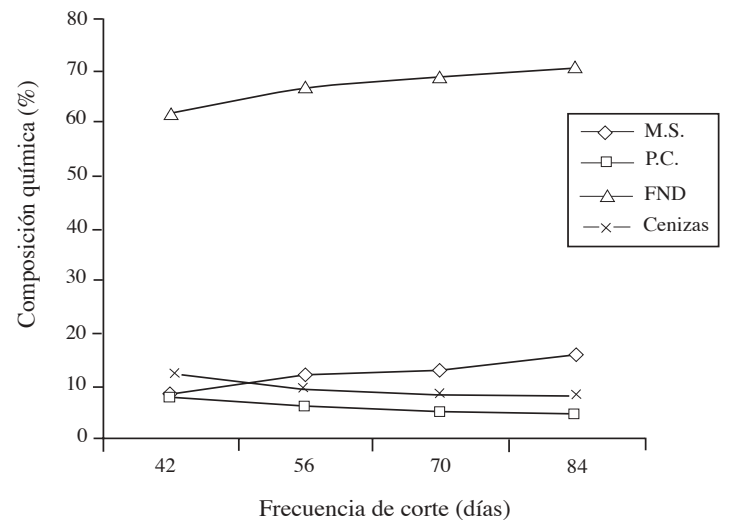

Figura 2. Composición química del tallo de la planta de ramio cortada en diferentes frecuencias. Cartago, Costa Rica. 2001. 
Se evidencia que el porcentaje de proteína cruda fue menor al disminuir la frecuencia entre cortes. El porcentaje de proteína cruda fue siempre inferior en tallos que en hojas.

Boschini y Rodríguez (2002) obtuvieron rendimientos $(\mathrm{kg} / \mathrm{ha} /$ corte $)$ de materia seca en tallos de 1021,1909 , 2084 y 2828 a los 42, 56, 70 y 84 días respectivamente.

\section{Calidad nutricional de la planta entera}

En la Figura 3 se muestra la variación en la composición química de la planta entera cortada en diferentes frecuencias.

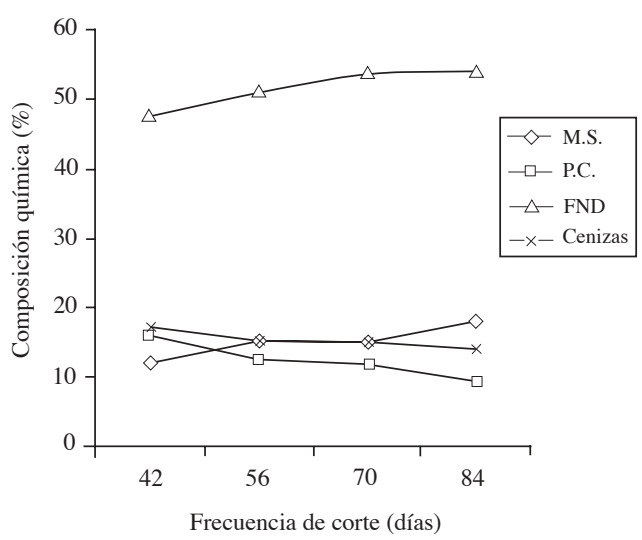

Figura 3. Composición química de la planta entera de ramio cortada en diferentes frecuencias. Cartago, Costa Rica. 2001.

La concentración de materia seca fue mayor al aumentar el intervalo de tiempo entre podas, pasando de un $12,32 \%$ a intervalos de corte cada 42 días hasta un $17,79 \%$ a intervalos de corte cada 84 días.

En el caso del porcentaje de proteína cruda, se observa una disminución del $67 \%$ al comparar esos mismos intervalos de corte. El contenido de fibra neutro detergente fue inferior a 55\%, mientras que el contenido de cenizas fue inferior a $17 \%$.

En el cultivo para la producción de fibra, Pereira (1943) reporta valores de proteína cruda en hojas entre 19 y $21 \%$, a edades menores de 70 días, como un indicativo de la buena nutrición de la planta en Brasil. Con estos valores, Santos et al. (1997) llevaron a cabo un experimento para medir el efecto de la sustitución del $50 \%$ de Pennisetum pupureum por ramio en la dieta de cabras, encontrando un incremento en la producción de leche de un $14 \%$ y un $18 \%$ en el peso corporal.

\section{CONCLUSIONES Y RECOMENDACIONES}

El porcentaje de materia seca se incrementó a medida que aumenta la edad del rebrote o el intervalo de tiempo entre podas sucesivas.

La calidad nutricional de la hoja de ramio disminuye a medida que aumenta la edad del rebrote, pues, el porcentaje de proteína cruda y fibra neutro detergente también disminuyen.

El follaje de ramio presentó contenidos de proteína cruda superiores a la mayoría de alimentos balanceados que se encuentran en el mercado nacional, lo que constituye una excelente fuente de alimentación animal.

En términos generales las hojas presentaron un mayor contenido de materia seca y proteína cruda que los tallos.

Considerando la variación en la calidad nutricional de la hoja, tallo y de la planta entera de ramio en las diferentes frecuencias de corte y para las condiciones en que se llevó a cabo este trabajo, se sugiere realizar los cortes cada 56 días.

Debido a que las plantaciones de ramio para la producción de forraje han sido poco estudiadas y a la poca información existente con respecto a la utilización de este forraje en la alimentación animal, es necesario hacer ensayos de fertilización, digestibilidad y producción en animales rumiantes.

\section{LITERATURA CITADA}

A.O.A.C. (Association of Official Analysis Chemistry). 1980. Methods of analysis. 13th ed. Washington D.C. USA. 168 p.

ARAUZ, C. 1984. Estudio de factibilidad de la producción y procesamiento del ramio (Bohemeria nivea $\mathrm{G}$ ). "Análisis de un caso". Tesis Ingeniero Agrónomo. Escuela de Economía Agrícola, Facultad de Agronomía. Universidad de Costa Rica. 192 p.

BERNAL, J. 1991. Pastos y forrajes tropicales: Producción y manejo. 2da edición. Banco Ganadero. Bogotá, Colombia. $544 \mathrm{p}$.

BOSCHINI, C.; RODRIGUEZ, A. 2002. Rendimiento del ramio (Bohemeria nivea (L) Gaud) cultivado para forraje. Agronomía Mesoamericana 13(1):31-36. 
GOERING, H.; VAN SOEST, P. 1970. Forage fiber analysis (apparatus, reagents, procedures and some applications). Agricultural Handbook No. 376. Washington D.C. ARS-USDA. $76 \mathrm{p}$.

HAVARD, B. 1969. Las plantas forrajeras tropicales. Editorial Blume. Barcelona, España. p. 231-232.

HIDALGO, C. 1982. Análisis del valor nutritivo del ramio (Bohemeria nivea $\mathrm{G}$.) en animales de laboratorio. Tesis Ingeniero Agrónomo. Escuela de Zootecnia, Facultad de Agronomía. Universidad de Costa Rica. 82 p.

HIMEBAUCH, K. 1967. El ramio, excelente forraje. Boletín Agrícola. Colombia. 657-10. 660 p.

LASSER, T. 1956. El cultivo del ramio para la producción de fibras y como forraje. Revista Pecuaria. 24(256):9-11.

PEREIRA, U. 1943. Cultura da ramí (Boehmeria nivea Gaud). Vamos para o campo No. 11. Edicao da Chacaras e Quintas. Sao Paulo. Brasil. 18 p.

RINCON, S. 1971. El ramio. Carta Agraria (Colombia). 251:5-8
SALAZAR, V. 1981. Análisis preliminar de la producción de ramio (Bohemeria nivea) en Costa Rica y sus perspectivas de mercado. Tesis Ingeniero Agrónomo. Escuela de Economía Agrícola, Facultad de Agronomía. Universidad de Costa Rica. 158 p.

SANTOS. L; CUNTRA, E; RODA, D; POZZI, C; POSSENTI, R; LEMOS, M. (1997). Producao de lette em caprinos alimentados com neveis crescentes de rami (Boehmeria nivea Gaud). Boletim de Industria Animal 52:153-159.

SAS. 1985. Statistical analysis system. SAS User's Guide; Statistics (Version 5 Ed.). SAS Institute Inc. Cary, NC. $373 \mathrm{p}$.

STEEL, R.; TORRIE, J. 1988. Bioestadística: principios y procedimientos. México, D.F. McGraw Hill. 633 p.

VASQUEZ, A. 1982. Estudio detallado de los suelos de la Estación Experimental de Ganado Lechero El Alto. Tesis Ingeniero Agrónomo. Escuela de Fitotecnia, Facultad de Agronomía. Universidad de Costa Rica. 36 p. 